\title{
Perfil do cuidador familiar do paciente com seqüela de acidente vascular encefálico
}

\author{
Profile of the family caregiver caring \\ for patients with sequels of cerebral vascular accident
}

$N$ atália da Rosa Fonseca ${ }^{1}$

Aline Fonseca Gueudeville Penna ${ }^{2}$

${ }^{1}$ Faculdade deFisioterapia,

Abstract This descriptive study using a qualitative approach aimed to identify who are the family caregivers and to understand how the caregiver is chosen amongst the family members of stroke patients. D ata were collected by means of a semi-structured questionnaireapplied to ten family caregivers. In addition, these caregivers were observed during the interview.The interviews were recorded, transcribed and analyzed. M ost of the caregi vers who participated in this study were females, married, partners and daughters, with a mean age of 54 years. Thestatements demonstrated that the "choice" of taking care is not so much an option but closely related to a feeling of obligation. Besides, this choice is also related to the affective relation established with the patient be fore the illness.

Key words Cerebral vascular accident, Caregivers, Home nursing, Family health
Resumo Este estudo descritivo, por meio de uma abordagem qualitativa, teve como objetivo conhecer quem são os cuidadores familiares e entender como sedá a escol ha do cuidador dentro da família de pacientes com seqüela de acidente vascular encefálico. Partici param do estudo dez cuidadoresfamiliares através de entrevistas eanotações de campo. As entrevistas foram gravadas e posteriormente transcritas e analisadas. Entre os entrevistados, predominaram as mulheres, casadas, cônjuges e filhos, com média etária de 54 anos. Em relação os fatores que determinam que o familiar assuma os cuidados, percebe-se que o cuidar é muito mais uma obrigação do que uma opção. N o entanto, esse sentimento de obrigação une-se ao afeto proveniente das relações estabelecidas anteriormente à doença.

Palavras-chave Acidente cerebrovascular, Cuidadores, Cuidados domiciliares de saúde, Saúde da família 
Introdução

O AcidenteVascular Encefálico (AVE) é a principal causa deinternações, mortalidadee deficiências na população brasileira, superando as doenças cardíacas e o câncer, as quais são as duas primeiras causas de morte nos países industrializados ${ }^{1}$.

A incidência do AVE émaior após os 65 anos, havendo um aumento do risco com a idade, dobrando a cada década após os 55 anos$^{2}$. Tendo em vista o rápido e intenso envelhecimento populacional brasileiro, estima-se que o AVE tenha cada vez mais relevância como um problema de saúde pública, até que os investimentos na pre venção desta doença passem a ser prioridade do sistema de saúde brasileiro.

A pós a hospitalização inicial, $80 \%$ dos sobreviventes do AVE retornam à comunidade ${ }^{3}$. Estes, entretanto, continuam requerendo cuidados especiais, que, considerando a cultura brasileira e as condições socioeconômicas da nossa população, geralmente são fornecidos pela família ${ }^{4}$.

A doença, especialmente a doença crônica, é sempre um acontecimento estressor que produz efeitos no doente e na família ${ }^{5}$. A família, ao vivenciar a crise provocada pela doença, experimenta inicialmente um desequilíbrio em sua capacidade de funcionamento normal, provocando alterações que envolvem afeto, finanças e re lações de poder que levam a um processo de re organização familiar6.

A pesar da doença afetar toda a família, normalmente a responsabilidade principal sobre 0 cuidado do pacienterecai sobreum único familiar, denominado cuidador principal 7 . Ele tem que lidar não só com as dificuldades do pacientecom a mobilidade, autocuidado e comunicação, como também com os possíveis déficits cognitivos, de pressão e mudança na personalidade?

Embora a designação do cuidador seja informal, geralmente obedece a quatro fatores relacionados com o parentesco, com freqüência maior para os cônjuges, o gênero, destacando-se o feminino, a proximidade física, considerando quem vivecom o paciente, ea proximidade afetiva, destacando-se a relação conjugal e entre pais e filhos ${ }^{6,8}$.

Este artigo é parte de um trabalho que buscou investigar as alterações na vida de cuidadores familiares de pessoas com AVE. Como o relatório final deste trabalho se apresentou extenso, foi objetivada a comunicação do conhecimento por meio de vários artigos. N este artigo, está sendo apresentado o conhecimento relacionado ao perfil do cuidador familiar, tendo como objetivo identificá-lo e entender como se dá a escolha do cuidador.

\section{Material e métodos}

Este é um estudo transversal de abordagem qualitativa, realizado com cuidadores familiares de pacientes adultos com seqüelas de AVE em tratamento no Instituto Bahiano de Reabilitação (IBR), Salvador, Bahia.

O IBR é uma instituição que oferece atendimento fisioterapêutico gratuito, entre outros serviços de saúde, e atende a adultos e crianças de baixa renda de Salvador e região metropolitana. Este local foi escolhido para a realização do estudo por incentivar eapoiar a realização de pesquisas científicas e pela experiência prévia da autora nesta instituição.

Participaram do estudo os membros das famílias de pacientes com seqüela de AVE, identificados como cuidadores familiares, por estarem assumindo a responsabilidade principal e nãoremunerada do cuidado domiciliar de uma pessoa, eque morassem no domicílio com o paciente, ou anexo a ele. Para definição do número de sujeitos entrevistados, foi utilizado o critério da saturação ou recorrência dos dados.

A coleta de dados foi realizada no período de junho e julho de 2006 e utilizou como instrumentos um roteiro de entrevista semi-estruturado e anotações em diário de campo. Os familiares foram entrevistados no IBR, no horário em que os pacientes estavam sendo atendidos nainstituição. As entrevistas foram gravadas e posteriormente transcritas e analisadas. Foram ainda aplicadas a escala de Barthel, que aborda as Atividades de Vida Diária (AVDs), e a escala de Lawton, sobre Atividades Instrumentais da Vida Diária (AVIs), para avaliar a capacidade funcional dos pacientes.

Todos os convidados aceitaram participar do estudo e assinaram o Termo de Consentimento Livree Esclarecido, garantindo os aspectos éticos previstos na Portaria n 196/96 do Conselho N acional de Saúde do M inistério da Saúde9. Para preservar o anonimato dos sujeitos da pesquisa, utilizaram-se nomes fictícios para identificá-los.

\section{Resultadosediscussão}

As dez entrevistas realizadas permitiram traçar um esboço do perfil do cuidador familiar, que geralmente é uma mulher, casada e que não tem 
ocupação fora de casa, dados que vão ao encontro da literatura consultada (Q uadro 1).

A maioria dos entrevistados neste estudo era do sexo feminino. Este dado corrobora com outros estudos $5^{5,7,7,10}$ que destacam o papel da muIher como cuidadora na nossa cultura. Historicamente, a mulher sempre foi responsável pelo cuidado, seja da casa ou dos filhos, enquanto o papel do homem era de trabalhar fora para garantir o provimento financeiro da família. Apesar de todas as mudanças sociais e na composição familiar, e dos novos papéis assumidos pela mulher, destacando-se a sua maior participação no mercado de trabalho, ainda espera-se que a mulher assuma essa função. Sendo assim, é comum que a mulher assuma os cuidados mesmo quando trabalha fora, o que acaba repercutindo em maiores limitações de tempo livre e implicações na vida social? ${ }^{7}$.

Geralmente, os homens participam do cuidado de uma forma secundária, através de ajuda material ou em tarefas externas, como o transportedo pacientee pagamento de contas ${ }^{7,10}$. Neste estudo, houve três cuidadores principais do sexo masculino e apesar de Euzébio ${ }^{10}$ relatar que "a mulher denota conseguir, melhor do que o homem, desempenhar o papel de cuidadora", dois destes homens foram os entrevistados que se mostraram mais adaptados a este papel, e surpreendentemente, seus depoimentos foram os que deixaram transparecer a maior resignação e afeto pelos pacientes.
A média de idade dos cuidadores encontrada neste estudo foi de 54 anos, o queseaproxima da média etária encontrada em outros estudos, como Euzébio ${ }^{10}$, com média de 52 anos, e $M$ artins et al. ${ }^{5}$, com média de 58 anos. 0 tempo que os cuidadores estavam exercendo esta atividade variou de um mês a quatro anos, com média de dois anos e quatro meses.

Todos os pacientes cuidados pelos entrevistados tinham sofrido apenas um episódio de AVE e apresentavam variados graus de depen dência para realização das atividades de vida diária, havendo desde pacientes com dependência total até aqueles com leve dependência, segundo escores obtidos pela escala de Barthel erelato dos cuidadores. A Tabela 1 mostra que a maioria dos pacientes era dependente para realização da higiene pessoal e banho e parcial mente dependente (necessidade de ajuda ou supervisão) para deambulação.

Ela não anda sozinha, ela perdeu os movimentos, ela não fala, ela não sabe tomar remédio, não sabe pedir nada... (M aria)

Ele não tem condições de fazer todas as coisas, colocar almoço, água pra tomar banho [...] eleanda sozinho, mastem queter uma pessoa com eleol hando, eu tenho medo delecair. [...]A gentefaz comida, a gente lava casa, lava roupa, a gente faz tudo, pra vocêter idéia atéa roupa demeu pai quem lava sou eu! (João)

Os escores obtidos pela Escala de Lawton, relativo às AVIs, revelam que todos os pacientes apresentavam alta dependência (Tabela 2). Mes-

Quadro 1. Características sociodemográficas dos cuidadores familiares de pacientes com seqüela de AVE. IBR, 2006.

\begin{tabular}{|l|l|c|c|l|l|l|c|}
\hline Nome & Parentesco & Sexo & I dade & $\begin{array}{c}\text { Estado } \\
\text { civil }\end{array}$ & Escolaridade & Ocupação & $\begin{array}{c}\text { Tempo de } \\
\text { cuidado }\end{array}$ \\
\hline M aria & Filha & F & 52 & Casada & Curso técnico & Téc. Enfermagem & 2 anos \\
\hline Fátima & Filha & F & 33 & Casada & Ens. fundamen. & Dona de casa & 1 mês \\
\hline Rita & Filha & F & 42 & Casada & Ensino médio & Aux. secretaria & 1 ano \\
\hline Aparecida & Esposa & F & 46 & Casada & Ensino médio & Dona de casa & 4 anos \\
\hline Dulce & Irmã & F & 65 & Divorciada & Ensino médio & Dona de casa & 3 anos \\
\hline Luzia & Irmã & F & 42 & Solteira & Ensino médio & Desempregada & 4 anos \\
\hline Tereza & M ãe & F & 72 & Solteira & Analfabeta & Aposentada & 3 anos \\
\hline Pedro & Esposo & M & 52 & Casado & Ens. fund. Incomp. & Capoteiro & 4 anos \\
\hline João & Filho & M & 58 & Casado & Curso técnico & Aposentado & 1 ano e 6 meses \\
\hline Bonfim & Esposo & M & 76 & Casado & Analfabeto & Aposentado & 1 ano \\
\hline
\end{tabular}


mo aqueles com leve dependência para realizações das AVDs obtiveram baixo escore para as AVIs, em alguns casos, conseqüência de alterações cognitivas e comportamentais secundárias à doença, que resultaram na perda de autonomia dos pacientes.

Ela não faz nada, tudo você tem que empurrar [...] ela anda, ela come, ela faz tudo, maséparada, não faz nada. (Luzia)

Porque ele não tá lembrando de al gumas coisas, ele age igual à criança, a mente dele regrediu muito. (Aparecida)

Em relação à escolaridade dos cuidadores, seis dos entrevistados declaram ter concluído o ensino médio; no entanto, a amostra também inclui dois analfabetos. É importante conhecer a escolaridade dos cuidadores, pois são eles que rece bem as informações e orientações da equipe de saúde, ea educação em saúde está muito ligada à capacidade de aprendizagem das pessoas ${ }^{11}$. Laham ${ }^{7}$ levanta a hipótese deque o nível deescolaridade possa influir nos sentimentos dos cuidadores, sendo que a pouca aprendizagem dificultaria a compreensão do que acontece com o paciente. No entanto, esta mesma autora concorda que os sentimentos dos cuidadores são conseqüência de uma interação complexa de fatores, indo muito além da informação.

0 parentesco tem uma influência decisiva na escolha do cuidador, destacando-se os cônjuges e os filhos ${ }^{7,8}$. Neste estudo, houve uma predominância para os filhos, seguidos pelos cônjuges, irmãos e pais.

Segundo Cattani eGirardon-Perlini ${ }^{8}$, os cônjuges são os principais a assumirem o cuidado, movidos principalmente por uma "obrigação

Tabela 1. Distribuição dos pacientes segundo grau de dependência para realização das AVDs de acordo com os resultados da aplicação da Escala de Barthel. IBR, 2006.

\begin{tabular}{lccc}
\hline & Dependente & Parcialmente dependente & Independente \\
\hline Alimentação & $30 \%$ & $50 \%$ & $20 \%$ \\
Banho & $70 \%$ & $*$ & $30 \%$ \\
Vestuário & $40 \%$ & $40 \%$ & $20 \%$ \\
Higiene pessoal & $70 \%$ & $*$ & $30 \%$ \\
Dejeções & $10 \%$ & $50 \%$ & $40 \%$ \\
Micção & $10 \%$ & $50 \%$ & $40 \%$ \\
Uso do vaso sanitário & $20 \%$ & $50 \%$ & $30 \%$ \\
Passagem cama-cadeira & $20 \%$ & $40 \%$ & $40 \%$ \\
Deambulação & $20 \%$ & $80 \%$ & $0 \%$ \\
Escadas & $20 \%$ & $80 \%$ & $0 \%$ \\
\hline
\end{tabular}

*Para os itens higiene pessoal ebanho, a escala de Barthel não oferece classificação intermediária entre dependência e independência.

Tabela 2. Distribuiç̧ão dos pacientes segundo grau de dependência para realização das AVIs de acordo com resultados da aplicação da escala de Lawton. IBR, 2006.

\begin{tabular}{lccc}
\hline & Dependente & Parcialmente dependente & Independente \\
\hline Uso do telefone & $60 \%$ & $30 \%$ & $10 \%$ \\
Compras & $80 \%$ & $20 \%$ & $0 \%$ \\
Preparo de refeições & $100 \%$ & $0 \%$ & $0 \%$ \\
Tarefas domésticas & $100 \%$ & $0 \%$ & $0 \%$ \\
Lavagem de roupa & $100 \%$ & $0 \%$ & $0 \%$ \\
Uso de meios de transporte & $20 \%$ & $80 \%$ & $0 \%$ \\
Manuseio de medicação & $60 \%$ & $40 \%$ & $0 \%$ \\
Gestão econômica & $100 \%$ & $0 \%$ & $0 \%$ \\
\hline
\end{tabular}


matrimonial", pelo projeto de vida comum assumido pelo casamento e o compromisso de estar junto na saúde e na doença.

Foi uma coisa que aconteceu e eu como marido teria que assumir de qualquer maneira. (Pedro).

Cattani e Girardon-Perlini ${ }^{8}$ ressaltam que a responsabilidade dos cuidadosétransferida para os filhos quando o cônjuge já é fal ecido ou não pode desempenhar este papel, fato que foi observado nesteestudo. N estecaso, também existeuma relação de obrigação, proveniente de valores impostos pela cultura familiar, ou seja, o cuidar é uma obrigação moral: quando eram crianças, os pais cuidaram dos filhos e agora, quando os pais estão dependentes, chegou a hora dos filhos cuidarem dos pais, e esse sentimento perdura através das gerações.

Ela cuidou muito bem de meu avô, muito bem de minha avó, e foi ela sozinha de vários irmãos queela teve, eagora não éjusto, né, ela pegar eficar na necessidade, aí, seria uma ingratidão [...] ela plantou pra colher agora. [...] A pessoa tem os fiIhos pra isso. (M aria)

Quando os filhos são cuidadores dos pais, muitas vezes o sentimento de obrigação confunde-se com uma retribuição de cuidados, somando-se também ao afeto.

É minha mãe, né, eu tenho obrigação de fazer, né, ela precisa de mim, de eu ajudar para fazer as coisas pra ela, que ela já fez muito e eu tenho que fazer por ela também. (Rita)

Pelo fato de quando eu me casei eu fiquei com ela um tempo, né, eela também [...] porqueela me ajudou quando os meus filhos tavam pequenos, assim, atédois anos, ela meajudou bastante [...] A verdade é que é obrigação da gente, eu falo assim: todo mundo tem que ter um filho porque nessas horas, vai contar com ele. (M aria)

N este estudo, as irmãs apareceram também como cuidadoras. Em um dos casos, o paciente não era casado e não tinha filhos, sendo os irmãos os parentes mais próximos. 0 que determinou que o cuidado fosse assumido por essa irmã foi o fato de morarem na mesma casa. Podese destacar aqui um outro fator importante, citado por alguns estudos na escolha do cuidador: a proximidade física ${ }^{6,8}$.

No outro caso, onde o cuidado foi assumido pela irmã, observa-se uma situação incomum. A paciente possui dois filhos, e apesar da responsabilidade culturalmente definida dos filhos no cuidado dos pais, os mesmos não assumiram o cuidado, possivelmente pela ausência do componente afetivo.

Dois filhos homens não assumiram nada, se eu não trago ela (de São Paulo), a essa altura ela tava morta, porque eles não tão nem aí. Ela tá aqui há dois anos, nenhum deles veio ver, só ligam quando bem entendem, a parte financeira nem [...] não mandam nada pra ela. (Luzia)

Essa ausência de val ores familiares se fez presente também quando a mãe do paciente, idosa, com problemas de saúde e residente em outra cidade, teve que assumir o cuidado do filho que foi abandonado pela esposa e filhos após a doença.

Jogaram na porta, sem falar esem andar, eu tive que cuidar, o que que eu ia fazer? [...] Não tem ninguém pra olhar ele, quem tem quecuidar sou eu [...] éobrigação de mãe, mãemesmo, porqueédifícil encontrar mãe assim, é muito difícil. (Tereza)

Por meio das verbalizações dos familiares, pôde-se perceber que, geralmente, o fato de assumir os cuidados éuma imposição das circunstâncias, não éuma opção, um ato pensado, muito menos decidido em conjunto. Na maioria dos casos, a pessoa se vê obrigada a assumir o cuidado por indisponibilidade de outras pessoas.

Só tem mesmo eu pra cuidar dele, porque os filhos não tem paciência. (Aparecida)

Porque sou eu sozinho em casa com ela, não tem outra pessoa. (Bonfim)

Algumas vezes, existem outros possíveis cuidadores na família, mas uma das pessoas assume o cuidado num ato impulsivo, ou vai assumindo pequenos cuidados e quando percebejá é o cuidador principal ${ }^{8}$. Cattani e Girardon-Perli$\mathrm{ni}^{8}$ relatam que, quanto mais o cuidador se envolveno cuidado, mais os não-cuidadores se afastam, sendo, portanto, o cuidado dificilmente transferível para outro familiar. Nesteestudo, isto pode ser constatado pelo fato de que os cuidadores entrevistados estão neste papel desde que o familiar retornou ao domićlio após a hospitalização. A transferência do cuidado esteve presente em apenas uma das famílias que participaram do estudo. N este caso, imediatamente após - AVE, a paciente passou a morar e ser cuidada por uma das filhas e, três meses após, outra filha assumiu o cuidado. Pôde-se observar um senso de cooperação muito grande nesta família, pois apesar da transferência do cuidado principal, os demais membros da família continuavam participando da assistência à paciente. Durante as diversas visitas da pesquisadora à instituição, a paciente sempre estava acompanhada por sua cuidadora principal euma outra filha eeventualmente uma neta.

Pra descansar minhas outras irmãs, eu peguei agora um pouquinho pra ver, né, se eu guentar e conseguir né, ela vai continuar lá. (Fátima) 
As duas cuidadoras que assumiram o cuidado do paciente quando os demais familiares 0 abandonaram foram as duas que expressaram claramentea vontade deinstitucionalizar ou contratar al guém para cuidar do doente, o que ainda não foi feito por falta de recursos financeiros.

A posentando ele, eu quero deixar lá (na instituição). (Tereza)

Totalmente! Se eu tivesse grana eu contratava uma enfermeira, uma psicóloga. (Luzia)

Os demais entrevistados, mesmo após terem relatado as dificuldades e limitações impostas às suas vidas, quando questionados sobre a vontade de deixar o cuidado para outra pessoa, afirmaram que gostariam de receber ajuda, mas não deabandonar o cuidado. A única justificativa encontrada por eles para justificar esse comportamento aparentemente contraditório é a relação afetiva estabelecida anteriormente à doença. 0 amor e compaixão que os moveram a assumir o cuidado os mantêm nessa jornada apesar de todas adversidades.

\section{Colaboradores}

NR Fonseca participou do delineamento do estudo, realizou e transcreveu as entrevistas, desenvolveu a análise dos dados e foi a redatora principal do artigo; AFG Penna participou da revisão crítica do artigo e redação final.

\section{Referências}

1. Bocchi SCM, Angelo M. Interação cuidador familiar - pessoa com AVC: autonomia compartilhada. Cien Saude Colet 2005; 10(3):729-738.

2. O'Sullivan S. Acidente Vascular encefálico. In: 0 'Sulivan S. Fisioterapia: avaliação e tratamento. $2^{\mathrm{a}}$ ed. Barueri: Manole; 2004. p. 519-565.

3. Han B, Haley W. Family caregiving for patients with stroke: Review and analysis. Stroke 1999; 30:1478-1485.

4. Lavinsky A, Vieira, T. Processo de cuidar de idosos com acidente vascular encefálico: sentimento dos familiares envolvidos. Acta Scientiarium. Health Sciences 2004; 26(1):41-45.

5. Martins T, Ribeiro JP, Garrett C. Estudo de validação dos Questionário de avaliação da sobrecarga para cuidadores informais. Psicologia, Saúde e Doenças 2003; 4(1):131-148.

6. Karsch U. Idosos dependentes: famílias e cuidadores. Cad Saúde Pública 2003; 19(3):861-866.

7. Laham CF. Percepção de perdas e ganhos subjetivos entre cuidadores de pacientes atendidos em um programa de assistência domiciliar [dissertação]. São Paulo (SP): Faculdade de M edicina, Universidade de São Paulo; 2003.

\section{Consideraçõesfinais}

Este estudo, ao abordar a temática dos cuidadores familiares, alerta os profissionais de saúde para a importância de conhecerem mais a fundo as famílias, pois se sabe que a saúde dos indivíduos possui uma estreita ligação com as crenças, valores, relações, direitos e deveres do sistema familiar.

É necessário conhecer as características, necessidades e expectativas da família, para prestar uma assistência mais direcionada, adequando as condutas à realidade de cada família e adaptando as orientações a cada tipo de cuidador e paciente.

É especialmente importante conhecer, orientar e ouvir o cuidador familiar, pois el eéa pessoa que está em contato mais próximo com o paciente e deve ser o maior aliado dos membros da equipe de saúde.
8. Cattani RB, Girardon-Perlini, N M O. Cuidar do idoso doente no domicílio na voz de cuidadores familiares. Revista Eletrônica de Enfermagem 2004; 6(2):254271.

9. Brasil. Ministério da Saúde. Conselho Nacional de Saúde, Resolução n 196/96 sobre pesquisa envolvendo seres humanos. Bioética 1996; 4(2):15-25.

10. Euzébio CV. $O$ perfil do cuidador familiar do paciente com seqüela de AVE [dissertação]. Salvador (BA): Universidade Católica do Salvador; 2005.

11. Resta DG, Budó M LD. A cultura e as formas de cuidar em família na visão de pacientes e cuidadores domiciliares. Acta Scientiarium. Health Sciencies 2004; 26(1):53-60.

Artigo apresentado em14/08/2006

A provado em 25/06/2007

Versão final apresentada em 09/07/2007 